\title{
Transgenic tobacco plants expressing antimicrobial peptide bovine lactoferricin show enhanced resistance to phytopathogens
}

\author{
Shiro Fukuta ${ }^{1, *}$, Kei-ichi Kawamoto ${ }^{2, a}$, Yuko Mizukami ', Yukie Yoshimura', \\ Jun-ichi Ueda', Michio Kanbe ${ }^{1}$ \\ ${ }^{1}$ Aichi Agricultural Research Center, Nagakute, Aichi 480-1193, Japan; ${ }^{2}$ Aichi College of Agriculture, Nagakute, Aichi \\ 480-1193, Japan \\ *E-mail: shirou_fukuta@pref.aichi.lg.jp Tel: +81-561-62-0085 Fax: +81-561-63-0815
}

Received February 27, 2012; accepted June 19, 2012 (Edited by T. Anai)

\begin{abstract}
Lactoferricin $\mathrm{B}$, the antimicrobially active $\mathrm{N}$-terminal peptide derived from acid pepsin hydrolysis of bovine lactoferrin, has broad spectrum antimicrobial activities. We expressed the lactoferricin gene in tobacco plants to evaluate its antimicrobial activity. The coding region for the chimeric peptide gene of the signal peptide from tobacco pathogenrelated protein (PR-1) and bovine lactoferricin was synthesized using the recombinant polymerase chain reaction (PCR) method. Transgenic tobacco plants expressing the lactoferricin gene were developed using the Agrobacterium-mediated transformation method. The lactoferricin B gene was integrated into the tobacco genome and its transcription was detected by PCR, Southern blot analysis, and reverse transcription PCR (RT-PCR), respectively. The transgenic tobacco plants were challenged with the pathogenic bacteria Pseudomonas syringae pv. tabaci and Botrytis cinerea. At 30 or 28 days postinoculation, the transgenic plants were still green and continued to grow, whereas the control plants were infected with bacterial or fungal pathogens from the roots to the tips, resulting in death of the plants. In conclusion, transgenic tobacco plants that overexpressed the lactoferricin gene, linked to the signal peptide of tobacco PR-1 protein under the control of a high expression constitutive promoter, showed enhanced resistance to bacterial (P. syringae pv. tabaci) and fungal (B. cinerea) diseases.
\end{abstract}

Key words: Lactoferricin, cationic peptide, transgenic tobacco, phytopathogens, disease resistance

Lactoferrin is a glycoprotein found in bovine whey protein fractions. Lactoferrin has multiple biological functions, mostly related to host defense, including broad-spectrum antimicrobial properties.

Lactoferricin B ( $\mathrm{Lfc})$ is a 25 -amino acid peptide with a molecular weight of 3,124 that originates from the $\mathrm{N}$-terminus of bovine lactoferrin (Bellamy et al. 1992a). Lfc has stronger antimicrobial activity against various human pathogenic bacteria (Aguilera et al. 1999; Bellamy et al. 1992b; Sánchez-Gómez et al. 2008; Shin et al. 1998; Wakabayashi et al. 2002), fungi (Bellamy et al. 1993), and viruses (Marr et al. 2009) compared to that of lactoferrin. The antimicrobial activity of Lfc against plant pathogenic bacteria (Zhang et al. 1998) and fungi (Muños and Marcos 2006) has also been studied. Lfc has characteristics of typical cationic antimicrobial peptides (Tomita et al. 2009), which are thought to be the result of actions on the cytoplasmic membrane of bacteria, such as the formation of pores, destabilization of the bilayer, thinning of the membrane, or depolarization of the membrane (Ulvatne et al. 2001).

Many studies have shown the expression of antimicrobial cationic peptides in plants, e.g., cecropin in tobacco (Hightower et al. 1994; Jaynes et al. 1993) and tomato (Jan et al. 2010), sarcotoxin in tobacco (Ohshima et al. 1999) and tomato (Radi et al. 2006), MsrA3 in potatoes (Osusky et al. 2004), and cecropinmelittin chimeric peptide in potato (Osusky et al. 2000). Transgenic plants showed considerably greater resistance to pathogens (Hightower et al. 1994; Jan et al. 2010; Jaynes et al. 1993; Ohshima et al. 1999; Osusky et al. 2000; Osusky et al. 2004) and parasitic weeds (Radi et al. 2006) than to the wild types.

Zhang et al. (1998) reported that transgenic tobacco expressing human lactoferrin protein demonstrated significant delays in developing bacterial wilt symptoms when inoculated with the bacterial pathogen Ralstonia solanacearum. They reported that lactoferricin, which has higher bactericidal activity and is resistant to pepsin digestion, could confer higher levels of bactericidal

a Present address: AISAN Seed Co., Ltd., Mie 4908-0802, Japan.

This article can be found at http://www.jspcmb.jp/

Published online August 30, 2012 


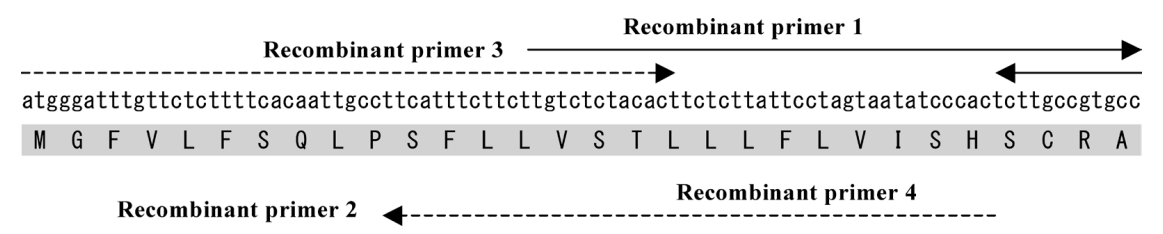

tttaaatgccgtcgttggcaatggcgtatgaagaagctcggagccccttcaataacatgcgttcgtcgtgccttttaa

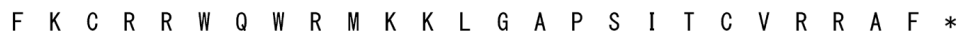

Figure 1. The sequences of the amino acids and the nucleotides of signal peptide of PR1 and lactoferricin. For improved plant expression, codon choice was made according to the codon usage in tobacco. Shadowed letters show the signal peptide of tobacco PR1 protein, and * shows the stop codon.

disease resistance to transgenic plants. In this study, we developed transgenic tobacco plants that carried the $L f \mathcal{c}$ gene fused to the signal peptide of tobacco pathogenrelated protein (PR-1) under the control of the enhanced cauliflower mosaic virus (CaMV) $35 \mathrm{~S}$ promoter. The effects of $L f c$ gene expression in transgenic tobacco plants against the phytopathogenic bacteria Pseudomonas syringae pv. tabaci and the fungi Botrytis cinerea were analyzed.

\section{Materials and methods}

\section{Assay of Lfc antibacterial activity}

Synthesized bovine Lfc ( $N$-FKC RRW QWR MKK LGA PSI TCV RRA F-C) was purchased from BioGate Co. (Gifu, Japan). The in vitro antibacterial activity of Lfc was determined by the method described by Zhang et al. (1998) with a slight modification. P. syringae pv. maculicola (PMC8301) and Xanthomonas campestris pv. vesicatoria (\#613) were a gift from Dr. Takikawa, University of Shizuoka. R. solanacearum (OE11) was collected in Aichi Prefecture, Japan. The bacteria were grown to OD600 of 0.3 in NB liquid medium (Difco), and $1 \mathrm{ml}$ aliquots were transferred to culture tubes. Synthetic Lfc was added to the culture tubes to obtain final concentrations of $100 \mu \mathrm{moll}^{-1}, 10 \mu \mathrm{moll}^{-1}, 1 \mu \mathrm{moll}^{-1}$ or $0 \mu \mathrm{moll}^{-1}$, respectively. The bacterial suspensions were serially diluted 10 -fold and plated on NB agar. The colonies were counted after an overnight culture.

\section{Plasmid construction}

The chimeric peptide gene coding region (Figure 1) of the signal peptide from tobacco PR-1 and $L f c(S i g-L f c)$ was synthesized by the recombinant polymerase chain reaction (PCR) method (Fujimoto et al. 1993). The first and second recombinant PCR were performed in a total volume of $100 \mu$ l. The first reaction contained $1 \times$ AmpliTaq Gold Buffer (Applied Biosystems), $0.25 \mathrm{mmoll}^{-1} \mathrm{dNTPs}, 1 \mu \mathrm{moll}^{-1}$ of recombinant primer 1 ( $5^{\prime}$-TTG TCT CTA CAC TTC TCT TAT TCC TAG TAA TAT CCC ACT CTT GCC GTG CC-3') and recombinant primer 2 (5'-CGA GCT TCT TCA TAC GCC ATT GCC AAC GAC GGC ATT TAA AGG CAC GGCAAGA-3'), and 2.5 units of AmpliTaq Gold (Applied Biosystems). The second reaction contained $1 \times$ AmpliTaq Gold Buffer, $0.25 \mathrm{mmoll}^{-1}$ dNTPs, $1 \mu \mathrm{moll}^{-1}$ of recombinant primer $3\left(5^{\prime}\right.$-ATG GGA TTT GTT

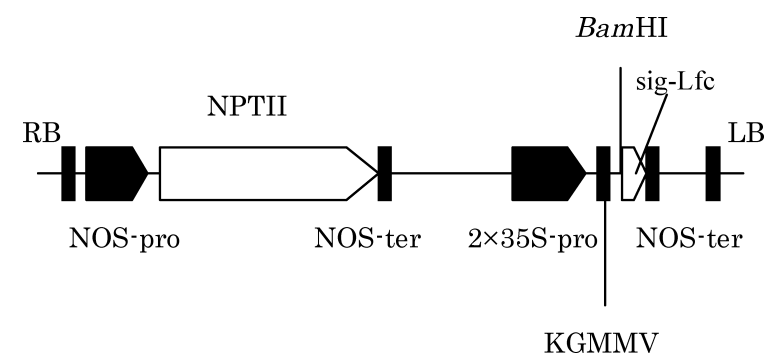

Figure 2. The expression constructs for sig-Lfc. The pEC-sigLfc plasmid expression vector for right and left border regions of the $\mathrm{Ti}$ plasmid; Nos-pro and Nos-ter, promoter and terminator, respectively, of the nopaline synthase gene; NPTII, neomycin phosphotransferase II; $2 \times 35$ S, duplicated enhancer CaMV 35 S promoter; KGMMV, 5' no coding region of Kyuri green mottle mosaic virus; sig-Lfc, peptide coding sequence of sig-Lfc.

\section{CTC TTT TCA CAA TTG CCT TCA TTT CTT CTT GTC TCT} ACA C-3') and recombinant primer 4 (5'-TTA AAA GGC ACG ACG AAC GCA TGT TAT TGA AGG GGC TCC GAG CTT CTT CA-3'), 2.5 units of AmpliTaq Gold, and $1 \mu$ l of the first PCR solution. The first and second PCR mixture were denatured for $9 \mathrm{~min}$ at $94^{\circ} \mathrm{C}$ and then amplified via five cycles of $94^{\circ} \mathrm{C}$ for $1 \mathrm{~min}, 45^{\circ} \mathrm{C}$ for $1 \mathrm{~min}$, and $72^{\circ} \mathrm{C}$ for $2 \mathrm{~min}$ followed by 20 cycles of $94^{\circ} \mathrm{C}$ for $1 \mathrm{~min}, 60^{\circ} \mathrm{C}$ for $1 \mathrm{~min}$, and $72^{\circ} \mathrm{C}$ for $2 \mathrm{~min}$. This was followed by a final extension period of $10 \mathrm{~min}$ at $72^{\circ} \mathrm{C}$. The PCR products were cloned into the pGEM T-Easy Vector System (Promega) and sequenced with the CEQ8000 System (Beckman Coulter). The vector including the Sig- $L f c$ gene was digested with BamHI and SacI. The DNA fragment containing the chimeric peptide was inserted into the pEC vector, which had a high-expression promoter, including the double enhancer of cauliflower mosaic virus $35 \mathrm{~S}$ promoter and the Kyuri green mottle mosaic virus (KGMMV) $5^{\prime}$ no coding region (Fukuta and Kanbe 2002). The binary vector pEC-sigLfc is shown in Figure 2.

\section{Plant material and transformation}

Tobacco (Nicotiana tabacum cv. Samsun) seeds were treated with $1 \% \mathrm{NaOCl}$ and $0.1 \%(\mathrm{v} / \mathrm{v})$ Tween 20 for $10 \mathrm{~min}$ and then rinsed three times with sterile deionized water. The sterilized seeds were germinated and grown on Murashige and Skoog's (MS) medium (Murashige and Skoog 1962) and maintained under a $16-\mathrm{h} / 8$-h (light/dark) photoperiod at $25^{\circ} \mathrm{C}$. Excised young leaves were co-cultivated with the overnight culture of 
Agrobacterium tumefaciens LBA4400 containing the pEC-sigLfc plasmid for $48 \mathrm{~h}$ at $25^{\circ} \mathrm{C}$ in the dark on co-culture medium [MS medium supplemented with $30 \mathrm{gl}^{-1}$ sucrose, $0.2 \mathrm{mgl}^{-1}$ naphthalene acetic acid (NAA), $2 \mathrm{mgl}^{-1}$ benzyladenine (BA), and $2.5 \mathrm{gl}^{-1}$ gellan gum]. The explants were transferred to selection medium after two days (co-culture medium supplemented with $250 \mathrm{mgl}^{-1}$ cefotaxim and $100 \mathrm{mgl}^{-1}$ kanamycin) at $25^{\circ} \mathrm{C}$ under a $16-\mathrm{h} / 8$-h (light/dark) photoperiod. When shoots appeared from explants, they were separated and transferred into root formation medium (half strength MS medium, $15 \mathrm{gl}^{-1}$ sucrose, $2.5 \mathrm{gl}^{-1}$ gellan gum, $250 \mathrm{mgl}^{-1}$ cefotaxime, and $100 \mathrm{mgl}^{-1}$ kanamycin).

\section{DNA isolation, PCR analysis, and Southern hybridization}

Genomic DNA was isolated from tobacco plant leaf tissue using the DNeasy Plant Mini Kit (Qiagen), according to the manufacturer's instruction. Integration of the Sig- $L f c$ gene into the plant genome was confirmed by PCR amplification of the CaMV 35 S promoter and the Sig- $L f c$ gene using the forward primer ( $5^{\prime}$-CGC CAA GCT TGC ATG CC-3') and the reverse primer ( $5^{\prime}$-TTA AAA GGC ACG ACG AAC - $\left.3^{\prime}\right)$. PCR products were analyzed on $1 \%$ agarose gels.

Young leaves were collected to isolate DNA according to the CTAB method (Murray and Thompson 1980). About $5 \mu \mathrm{g}$ of DNA samples were digested with BamHI and used for Southern analysis using $L f c$ gene as the probe. The Gene Images RandomPrime Labeling and Detection System (GE Healthcare) was used to detect the transgene.

\section{Analysis of Lfc gene expression}

Total RNA was extracted from $100 \mathrm{mg}$ of young leaves with the RNeasy Plant Mini Kit (Qiagen) according to the manufacturer's instructions. Total RNA was reverse-transcribed with an oligo-dT primer using Ready-To-Go ${ }^{\mathrm{Tt}}$ You-Prime FirstStrand Beads (Roche Applied Science). The resulting cDNA was used as a template for the PCR reaction to amplify the $L f c$ gene with the Lfc-F ( $5^{\prime}$-TTT AAA TGC CGT CGT TGG CAA - $3^{\prime}$ ) and Lfc-B primers ( $5^{\prime}$-AAA GGC ACG ACG AAC GCA TGT $\left.-3^{\prime}\right)$. PCR products were analyzed on $2 \%$ agarose gels.

\section{Evaluation of antibacterial and antifungal activity in transgenic tobacco plants}

Antibacterial and antifungal assays using the plant pathogens $P$. syringae pv. tabaci and B. cinerea were performed in a plant culture box with two leaf-stage tobacco plants grown in MS medium. Bacterial solution $(100 \mu \mathrm{l})$ containing $10^{2}$ P. syringae cells and $100 \mu \mathrm{l}$ of spore solution containing $10^{2} \mathrm{~B}$. cinerea spores were applied to the bottom of the culture box and incubated at $25^{\circ} \mathrm{C}$ under a $16-\mathrm{h} / 8$-h (light/dark) photoperiod. The tests were performed using six plants infected with $P$. syringae and eight plants infected with $B$. cinerea. An infection rate was calculated according to the following formula:

\author{
Infection rate \\ $=$ (the number of total infected plants/ \\ the number of total checked plants) $\times 100$
}

The mean and standard deviations were calculated based on three replications.

\section{Results}

Evaluation of biological activity of synthetic lactoferricin against plant pathogenic bacteria

The biological activity of synthetic Lfc was evaluated against three strains of plant pathogenic bacteria, $P$. syringae pv. maculicola (PMC8301), X. campestris pv. vesicatoria (\#613), and R. solanacearum (OE1-1). As a result of the growth inhibition experiment, even $1 \mu \mathrm{moll}^{-1}$ Lfc showed bactericidal activity against the three bacterial species (Table 1). Furthermore, P. syringae and $X$. campestris were not detected at $100 \mu \mathrm{moll}^{-1}$.

\section{Integration and expression of the Lfc gene}

It is imperative that $\mathrm{Lfc}$ is translocated into the intercellular spaces to make it effective for controlling bacterial and fungal diseases in tobacco. This was achieved by fusing Lfc to the signal peptide from tobacco PR-1a, which directs secretion of the PR-1a protein into the intercellular spaces in tobacco. The Sig- $L f c$ gene was constructed using the recombinant PCR method.

Tobacco (Nicotiana tabacum cv. Samsun) was transformed with pEC-sigLfc by A. tumefaciens-mediated transformation method. Integration of the $L f c$ gene into the genomic DNA of tobacco plants was confirmed by PCR amplification of the CaMV 35S promoter and $L f c$ gene sequences. A suitable $970 \mathrm{bp}$ DNA fragment was detected in $\mathrm{T}_{0}$ transgenic tobacco lines (No. 33 and 74), whereas no bands were detected in the untransformed control tobacco plant (data not shown).

Table 1. Antibacterial activity of Lfc against three phytopathogenic bacteria

\begin{tabular}{ccc}
\hline Bacterial species & $\begin{array}{c}\mu \text { M Lfc } \\
\text { concentration }\end{array}$ & $\log 10 \mathrm{CFU}^{*} / \mathrm{ml}$ \\
\hline P. syringae & 0 & $9.47 \pm 0.12$ \\
& 1 & $5.51 \pm 0.45$ \\
& 10 & $4.19 \pm 0.04$ \\
X. campestris & 100 & $<1$ \\
& 0 & $9.06 \pm 0.23$ \\
R. solanacearum & 1 & $7.67 \pm 0.12$ \\
& 10 & $5.51 \pm 0.17$ \\
& 100 & $<1$ \\
& 1 & $10.67 \pm 0.09$ \\
& 10 & $7.80 \pm 0.11$ \\
& 100 & $6.57 \pm 0.06$ \\
& & $5.69 \pm 0.29$
\end{tabular}

* Colony-formation unit. 


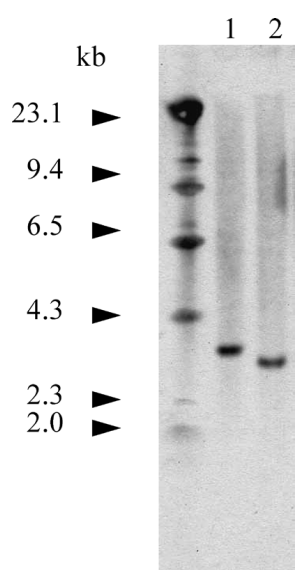

Figure 3. Southern blot analysis of transgenic tobacco plants carrying the Lfc gene. DNA from transgenic tobacco plants No. 33 (lane 1) and No. 74 (lane 2) was digested with BamHI. The Southern blot was probed with Lfc gene. The molecular weight marker was lambda/HindIII.

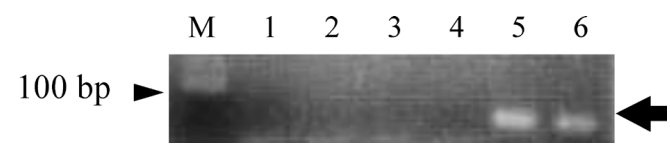

Figure 4. Analysis of the Lfc gene expression in the transgenic tobacco plants by RT-PCR. PCR products from RNA extracted from control (lane 1) and transgenic plants No. 33 (lane 2) and No. 74 (lane 3) without reverse transcription, and RT-PCR products from RNA extracted from control (lane 4) and transgenic plants No. 33 (lane 5) and No. 74 (lane 6) were analyzed. Allow indicates Lfc gene amplified by RT-PCR. Lane M, 100 bp ladder.

Furthermore, the transgenic tobacco lines were confirmed to have the transgene using Southern blot analysis. As a result, a signal was detected in No. 33 and 74 (Figure 3), which revealed that the $L f c$ gene was transformed in these two lines.

$L f c$ expression was tested at the RNA level using RT-PCR. The appropriate $78 \mathrm{bp}$ DNA fragments were detected in two transgenic lines (Figure 4, lanes 5 and 6), whereas no bands appeared in the untransformed control tobacco plants (Figure 4, lane 4).

\section{Evaluation of antimicrobial activity in transgenic tobacco}

To evaluate the resistance to bacterial disease, control tobacco plants and two kanamycin resistant $\mathrm{T}_{1}$ transgenic lines (No. 33 and 74) were challenged with P. syringae pv. tabaci, an endemic pathogen of wildfire disease.

Figure 5A shows the progression of $P$. syringae infection rate. The first symptoms were observed on the lower leaves in control and transgenic tobacco plants nine days post-infection. The infection rate of control tobacco increased immediately and all control plants were more or less damaged by bacterial infection, 16 days post-infection, resulting in the yellowing of leaves and softening of stems. In contrast, symptoms in the transgenic tobacco plants were delayed. The average infection rates were much lower than those in the control plants. At 30 days post inoculation, the control plants were infected with the disease from the roots to the tips, resulting in death of the plants. However, the transgenic plants were still green and continued to grow (Figure 5B).

To investigate the ability of transgenic tobacco plants to resist fungal infection, control tobacco plants and two kanamycin resistant $T_{1}$ transgenic lines (No. 33 and 74) were challenged with a pathogenic fungus (B. cinerea), and symptoms were recorded. The results are shown in Figure 6A. The fungus had grown all over the surface of the MS medium, and the roots and stems of the control plants were damaged 6 days post-inoculation. The control plants were infected from the roots to the tips 28 days post-inoculation, and five control plants were dead. In contrast, symptoms in the transgenic tobacco plants were delayed until 11 days post-inoculation. The average infection rates were much lower in the transgenic plants than those in control plants. The control plants were damaged 28 days post-inoculation, resulting in yellowing of leaves. However, the transgenic plants were still green and continued to grow normally (Figure 6B).

\section{Discussion}

Lactoferrin is an iron-binding glycoprotein in the transferrin family. A high concentration of lactoferrin is found in human milk and has been suggested to have several biological activities, including protection from pathogens, regulation of iron absorption, modulation of the immune system, and cellular growth promoting activity (Lönnerdal and Iyer 1995). Recombinant lactoferrin has been produced in plants to protect against plant pathogenic bacteria (Mitra and Zhang 1994; Zhang et al. 1998) and to increase nutritive value (Nandi et al. 2002; Nandi et al 2005). Lfc is the antimicrobial fragment derived from the full length lactoferrin protein upon pepsin cleavage. Lfc has characteristics of typical cationic antimicrobial peptides and higher antimicrobial activity than that of lactoferrin. Moreover, Lfc is not toxic to plant or animal cells (Muños and Marcos 2006). In the present study, transgenic tobacco plants expressing the $L f c$ gene were developed to enhance resistance against a broad spectrum of plant pathogens. As a result, Lfc exhibited bactericidal activity as high as bactericidal peptides, such as sarcotoxin IA derived from fresh fly Sarcophaga peregrina (Ohshima et al. 1999) and cecropin derived from giant silk moth Hylophora cecropiaie (Hightower et al. 1994; Jan et al. 2010; Jaynes et al. 1993).

Trials for the overexpression of bactericidal peptides under the control of the CaMV35S promoter have been conducted without positive results, possibly due to the instability of the expressed peptides (Hightower et al. 1994; Sharma et al. 2000; Zhang et al. 1998). Ohshima 


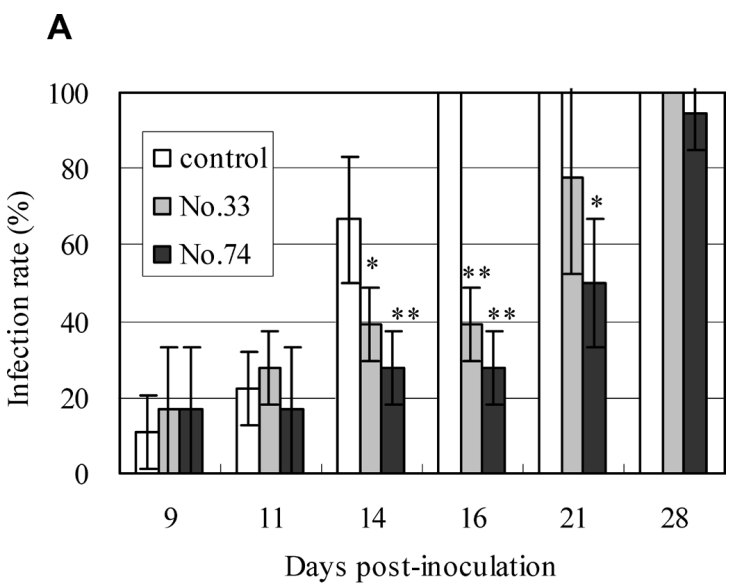

B

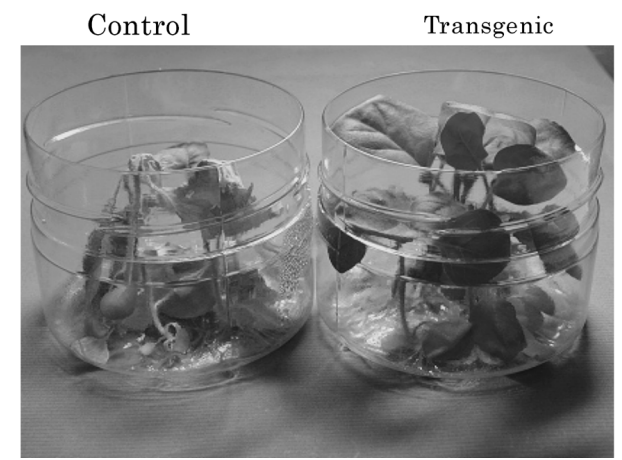

Figure 5. Transgenic tobacco challenged with the bacterial pathogen P. syringae pv. tabaci. Progression of the infection rate in transgenic tobacco plants (No. 33 and No. 74) and control tobacco plants (A). Points represent the mean of three replicates inoculations using 6 plants. Vertical bars represent standard deviations of three replications. Differences between values compared with control plants were tested for significance with Student's $t$-test $(* p<0.05, * * p<0.01)$. Transgenic (No. 74) and control tobacco plants on 30 days post-inoculation (B).

et al. (1999) and Osusky et al. (2000) reported that antimicrobial peptides overproduced by a strong promoter have antimicrobial activity in transgenic plants. They succeeded in improving the resistance against bacterial and fungal disease. High expression promoter, which is an artificial constitutive promoter including tandem repeats of the $5^{\prime}$ enhancer sequence of the CaMV35S promoter and the $5^{\prime}$ no coding region of KGMMV, was generated in this study. This artificial promoter could express the GUS protein at a 10 times higher level in comparison with that of the original $35 \mathrm{~S}$ promoter (Fukuta and Kanbe 2002).

Moreover, Lfc must be secreted outside the cells for effective protection against pathogenic bacteria and fungi (Ohshima et al. 1999). The PR-1a signal peptide has been successfully used to translocate expressed proteins or peptides to the apoplast (van Esse et al. 2006). Ohshima et al. (1999) and Sharma et al. (2000) reported that transgenic plants expressing the cationic bactericidal peptide as a form of fusion protein with

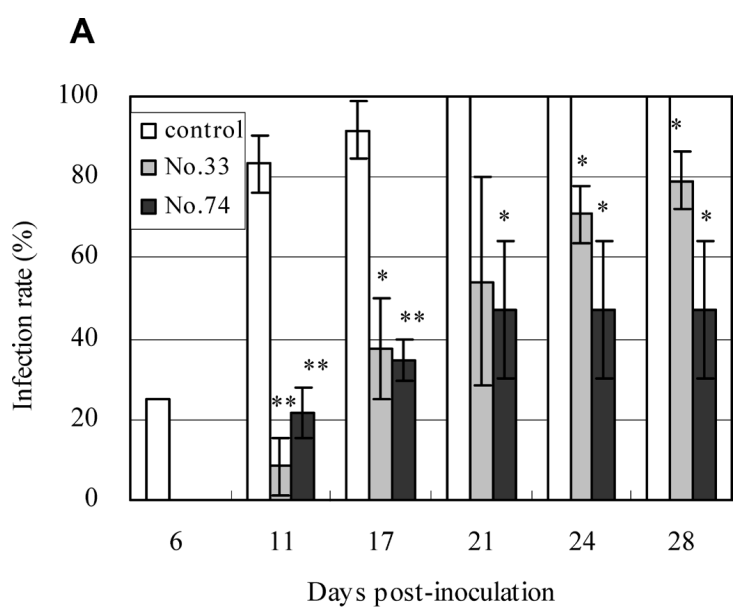

B

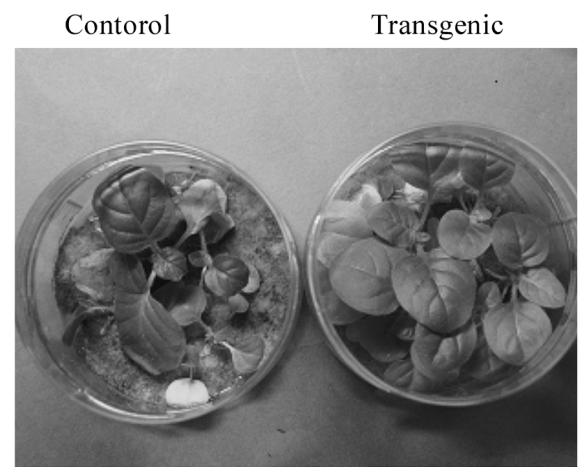

Figure 6. Transgenic tobacco plants challenged with the fungal pathogen $B$. cinerea. Progression of the infection rate in transgenic tobacco plants (No. 33 and No. 74) and control tobacco plants (A). Points represent the mean of three replicates inoculations using 8 plants. Vertical bars represent standard deviations of three replications. Differences between values compared with control plants were tested for significance with Student's $t$-test $(* p<0.05, * * p<0.01)$. Transgenic (No. 74) and control tobacco plants on 28 days post-inoculation (B).

the signal peptide are highly resistant to bacterial disease. Therefore, we used the signal peptide of the tobacco pathogenesis-related protein PR-1a to transfer Lfc peptides to the apoplast. As a result, the transgenic tobacco plants were highly resistant to $P$. syringae pv. tabaci and B. cinerea inoculation owing to the distinct delay in development of symptoms. Lfc peptides should be expected to secret into apoplast. Accumulation of the antimicrobial peptide in the apoplast should effectively enhance host resistance to pathogens that invade through the intercellular space.

Lfc has been reported to have high antimicrobial activity in vitro (Bellamy et al. 1993; Shin et al. 1998; Wakabayashi et al. 2002). Zhang et al. (1998) found that Lfc antibacterial activity is higher than that of shiva-1, which is one of the most widely reported bactericidal peptides. In the present study, Lfc was also demonstrated to have extremely high antibacterial activity against $P$. syringae, $X$. campestris, and $R$. solanacearum, which represent plant pathogenic bacteria (Table 1). In addition, 
Lfc has antiviral (Andersen et al. 2001; Marr et al. 2009), antitumour (Iigo et al. 1999; Yoo et al. 1997), and antiinflammatory activities (Levay and Viljoen 1995). Introducing the $L f c$ gene into crops and fruit plants is one method to develop plant resistance to bacterial and fungal diseases and to produce functional food for human health.

\section{Acknowledgments}

We would like to thank Dr. Takikawa for generous gift P. syringae pv. maculicola (PMC8301) and X. campestris pv. vesicatoria (\#613), and Enago (http://www.enago.jp) for the English language review.

\section{References}

Aguilera O, Ostolaza H, Quirós LM, Fierro JF (1999) Permeabilizing action of an antimicrobial lactoferricin-derived peptide on bacterial and artificial membranes. FEBS Lett 462: 273-277

Andersen JH, Osbakk SA, Vorland LH, Traavik T, Gutteberg TJ (2001) Lactoferrin and cyclic lactoferricin inhibit the entry of human cytomegalovirus into human fibroblasts. Antiviral Res 51: 141-149

Bellamy W, Takase M, Yamauchi K, Wakabayashi H, Kawase K, Tomita M (1992a) Identification of the bactericidal domain of lactoferrin. Biochim Biophys Acta 1121: 130-136

Bellamy W, Takase M, Wakabayashi H, Kawase K, Tomita M (1992b) Antibacterial spectrum of lactoferricin B, a potent bactericidal peptide derived from the $\mathrm{N}$-terminal region of bovine lactoferrin. J Appl Bacteriol 73: 472-479

Bellamy W, Wakabayashi H, Takase M, Kawase K, Shimamura S, Tomita M (1993) Killing of Candida albicans by lactoferricin B, a potent antimicrobial peptide derived from the $\mathrm{N}$-terminal region of bovine lactoferrin. Med Microbiol Immunol 182: 97-105

Fujimoto H, Itoh K, Yamamoto M, Kyozuka J, Shimamoto K (1993) Insect resistant rice generated by introduction of a modified $\delta$-endotoxin gene of Bacillus thuringiensis. Biotechnology 11: $1151-1155$

Fukuta S, Kanbe M (2002) Variants of the cauliflower mosaic virus $35 \mathrm{~S}$ promoter for enhanced gene expression in transgenic tobacco. Res Bull Aichi Agric Res Ctr 34: 55-59

Hightower R, Baden C, Penzes E, Dunsmuir P (1994) The expression of cecropin peptide in transgenic tobacco does not confer resistance to Pseudomonas syringae pv tabaci. Plant Cell Rep 13: 295-299

Iigo M, Kuhara T, Ushida Y, Sekine K, Moore MA, Tsuda H (1999) Inhibitory effects of bovine lactoferrin on colon carcinoma 26 lung metastasis in mice. Clin Exp Metastasis 17: 35-40

Jan PS, Huang HY, Chen HM (2010) Expression of a synthesized gene encoding cationic peptide cecropin B in transgenic tomato plants protects against bacterial diseases. Appl Environ Microbiol 76: 769-775

Jaynes JM, Nagpala P, Destéfano-Beltrán L, Huang JH, Kim JH, Denny T, Cetiner S (1993) Expression of cecropin B lytic peptide analog in transgenic tobacco confers enhanced resistance to bacterial wilt caused by Pseudomonas solanacearum. Plant Sci 89: $43-53$

Lee TJ, Coyne DP, Clemente TE, Mitra A (2002) Partial resistance to bacterial wilt in transgenic tomato plants expressing antibacterial lactoferrin gene. J Am Soc Hortic Sci 127: 158-164
Levay PF, Viljoen M (1995) Lactoferrin: a general review. Haematologica 80: 252-267

Lönnerdal B, Iyer S (1995) Lactoferrin: molecular structure and biological function. Annu Rev Nutr 15: 93-110

Marr AK, Jenssen H, Moniri MR, Hancock REW, Panté N (2009) Bovine lactoferrin and lactoferricin interfere with intracellular trafficking of Herpes simplex virus-1. Biochimie 91: 160-164

Mitra A, Zhang Z (1994) Expression of a human lactoferrin cDNA in tobacco cells produces antibacterial protein(s). Plant Physiol 106: 977-981

Muñoz A, Marcos JF (2006) Activity and mode of action against fungal phytopathogens of bovine lactoferricin-derived peptides. $J$ Appl Microbiol 101: 1199-1207

Murashige T, Skoog F (1962) A revised medium for rapid growth and bioassays with tobacco tissue culture. Physiol Plant 15: 473-479

Murray MG, Thompson WF (1980) Rapid isolation of high molecular weight plant DNA. Nucleic Acids Res 8: 4321-4325

Nandi S, Yalda D, Lu S, Nikolov Z, Misaki R, Fujiyama K, Huang N (2005) Process development and economic evaluation of recombinant human lactoferrin expressed in rice grain. Transgenic Res 14: 237-249

Nandi S, Suzuki YA, Huang J, Yalda D, Pham P, Wu L, Bartley G, Huang N, Lönnerdal B (2002) Expression of human lactoferrin in transgenic rice grains for the application in infant formula. Plant Sci 163: 713-722

Ohshima M, Mitsuhara I, Okamoto M, Sawano S, Nishiyama K, Kaku H, Natori S, Ohashi Y (1999) Enhanced resistance to bacterial diseases of transgenic tobacco plants overexpressing sarcotoxin IA, a bactericidal peptide of insect. J Biochem 125: 431-435

Osusky M, Osuska L, Hancock RE, Kay WW, Misra S (2004) Transgenic potatoes expressing a novel cationic peptide are resistant to late blight and pink rot. Transgenic Res 13: 181-190

Osusky M, Zhou G, Osuska L, Hancock RE, Kay WW, Misra S (2000) Transgenic plants expressing cationic peptide chimeras exhibit broad-spectrum resistance to phytopathogens. Nat Biotechnol 18: 1162-1166

Radi A, Dina P, Guy A (2006) Expression of sarcotoxin IA gene via a root-specific tob promoter enhanced host resistance against parasitic weeds in tomato plants. Plant Cell Rep 25: 297-303

Sánchez-Gómez S, Lamata M, Leiva J, Blondelle SE, Jerala R, Andrä J, Brandenburg K, Lohner K, Moriyón I, Martínez-deTejada G (2008) Comparative analysis of selected methods for the assessment of antimicrobial and membrane-permeabilizing activity: a case study for lactoferricin derived peptides. BMC Microbiol 8: 196

Sharma A, Sharma R, Imamura M, Yamakawa M, Machii H (2000) Transgenic expression of cecropin $\mathrm{B}$, an antibacterial peptide from Bombyx mori, confers enhanced resistance to bacterial leaf blight in rice. FEBS Lett 484: 7-11

Shin K, Yamauchi K, Teraguchi S, Hayasawa H, Tomita M, Otsuka Y, Yamazaki S (1998) Antibacterial activity of bovine lactoferrin and its peptides against enterohaemorrhagic Escherichia coli O157:H7. Lett Appl Microbiol 26: 407-411

Tomita M, Wakabayashi H, Shin K, Yamauchi K, Yaeshima T, Iwatsuki K (2009) Twenty-five years of research on bovine lactoferrin applications. Biochimie 91: 52-57

Ulvatne H, Haukland HH, Olsvik Ø, Vorland LH (2001) Lactoferricin B causes depolarization of the cytoplasmic membrane of Escherichia coli ATCC 25922 and fusion of negatively charged liposomes. FEBS Lett 492: 62-65 
van Esse HP, Thomma BPHJ, van't Klooster JW, de Wit PJGM (2006) Affinity-tags are removed from Cladosporium fulvum effector proteins expressed in the tomato leaf apoplast. J Exp Bot 57: 599-608

Wakabayashi H, Teraguchi S, Tamura Y (2002) Increased Staphylococcus-killing activity of an antimicrobial peptide, lactoferricin B, with minocycline and monoacylglycerol. Biosci Biotechnol Biochem 66: 2161-2167
Yoo Y-C, Watanabe S, Watanabe R, Hata K, Shimazaki K, Azuma I (1997) Bovine lactoferrin and lactoferricin, a peptide derived from bovine lactoferrin, inhibit tumor metastasis in mice. Jpn J Cancer Res 88: 184-190

Zhang Z, Coyne DP, Vidaver AK, Mitra A (1998) Expression of human lactoferrin cDNA confers resistance to Ralstonia solanacearum in transgenic tobacco plants. Phytopathology 88 : 730-734 